\title{
Understanding the structural characteristics of water-soluble phenolic compounds from four pretreatments of corn stover and their inhibitory effects on enzymatic hydrolysis and fermentation
}

\author{
Xiangxue Chen ${ }^{1 \dagger}$, Rui Zhai ${ }^{1 \dagger}$, Ying Li ${ }^{1}$, Xinchuan Yuan ${ }^{1}$, Zhi-Hua Liu ${ }^{2}$ and Mingjie Jin ${ }^{1 *}$ (e)
}

\begin{abstract}
Background: For bioethanol production from lignocellulosic biomass, phenolics derived from pretreatment have been generally considered as highly inhibitory towards enzymatic hydrolysis and fermentation. As phenolics are produced from lignin degradation during pretreatment, it is likely that the pretreatment will exert a strong impact on the structure of phenolics, resulting in varied levels of inhibition of the bioconversion process. Despite the extensive studies on pretreatment, it remains unclear how pretreatment process affects the properties of generated phenolics and how the inhibitory effect of phenolics from different pretreatment varies on enzymatic hydrolysis and fermentation.

Results: In this study, the structural properties of phenolic compounds derived from four typical pretreatment [dilute acid (DA), liquid hot water pretreatment (LHW), ammonia fiber expansion (AFEX) and alkaline pretreatment (AL)] were characterized, and their effect on both enzymatic hydrolysis and fermentation were evaluated. The inhibitory effect of phenolics on enzymatic hydrolysis followed the order: AFEX $>L H W>D A>A L$, while the inhibitory effect of phenolics on Zymomonas mobilis 8b strain fermentation followed the order: AL $>$ LHW $>$ DA $>$ AFEX. Interestingly, this study revealed that phenolics derived from AFEX showed more severe inhibitory effect on enzymatic hydrolysis than those from the other pretreatments at the same phenolics concentrations (note: AFEX produced much less amount of phenolics compared to AL and DA), while they exhibited the lowest inhibitory effect on fermentation. The composition of phenolics from different pretreatments was analyzed and model phenolics were applied to explore the reason for this difference. The results suggested that the amide group in phenolics might account for this difference.

Conclusions: Pretreatment process greatly affects the properties of generated phenolics and the inhibitory effects of phenolics on enzymatic hydrolysis and fermentation. This study provides new insight for further pretreatment modification and hydrolysate detoxification to minimize phenolics-caused inhibition and enhance the efficiency of enzymatic hydrolysis and fermentation.
\end{abstract}

Keywords: Lignocellulosic biomass, Phenolic inhibition, Pretreatment, Enzymatic hydrolysis, Fermentation

\footnotetext{
*Correspondence: jinmingjie@njust.edu.cn

${ }^{+}$Xiangxue Chen and Rui Zhai contributed equally to this work

1 School of Environmental and Biological Engineering, Nanjing University

of Science and Technology, 200 Xiaolingwei Street, Xuanwu District,

Nanjing 210094, China

Full list of author information is available at the end of the article
}

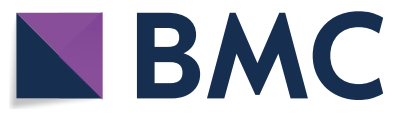

(c) The Author(s) 2020. This article is licensed under a Creative Commons Attribution 4.0 International License, which permits use, sharing, adaptation, distribution and reproduction in any medium or format, as long as you give appropriate credit to the original author(s) and the source, provide a link to the Creative Commons licence, and indicate if changes were made. The images or other third party material in this article are included in the article's Creative Commons licence, unless indicated otherwise in a credit line to the material. If material is not included in the article's Creative Commons licence and your intended use is not permitted by statutory regulation or exceeds the permitted use, you will need to obtain permission directly from the copyright holder. To view a copy of this licence, visit http://creativeco mmons.org/licenses/by/4.0/. The Creative Commons Public Domain Dedication waiver (http://creativecommons.org/publicdomain/ zero/1.0/) applies to the data made available in this article, unless otherwise stated in a credit line to the data. 


\section{Background}

Bioconversion of lignocellulosic biomass to bioethanol has been considered as a promising strategy to circumvent global warming and solve the issue of long-term global energy insecurity [1]. Due to the recalcitrance of biomass, pretreatment is needed to disrupt the cell wall structure and increase the accessibility of cellulose to cellulases [2]. Although pretreatment is necessary for efficient enzymatic hydrolysis and ethanol production, it releases various soluble degradation products that may significantly inhibit hydrolytic enzymes and fermenting microorganisms [3, 4]. The pretreatment-derived degradation products include phenolics (lignin derivatives), furfural, acetic acid, hydroxymethyl furfural (HMF), etc. The effect of furfural, acetic acid and hydroxymethyl furfural (HMF) on enzymatic hydrolysis and fermentation has been widely studied. For example, it has been reported that acetic acid showed no significant inhibition on cellulases at a comparatively low concentration of $2 \mathrm{~g} / \mathrm{L}$, while furfural inhibited cellulases at the same concentration. In addition, it has been found that $1.4 \mathrm{~g} / \mathrm{L}$ of the furans significantly delayed both glucose and xylose fermentation and HMF at same concentration showed a stronger inhibitory effect on glucose fermentation than furfural did [5]. In addition, the inhibitory effect of xylooligosaccharides derived from pretreatment on enzymatic hydrolysis of cellulose has been widely studied [6-8]. It has been found that cellulase inhibition by xylooligosaccharides was dependent on concentrations and structures. At relatively high concentrations $(2-6 \mathrm{~g} / \mathrm{L})$, xylo-oligosaccharides reduced the hydrolytic activities of key cellulases and significantly inhibited cellulose hydrolysis $[8,9]$. Different from these degradation products, the water-soluble phenolic compounds mainly derived from lignin have been considered as highly inhibitory compounds, which could strongly inhibit both enzymatic hydrolysis and fermentation at very low concentrations $[10,12]$. However, the studies on phenolics inhibition studies were quite limited; it remains unclear that how the inhibitory effect of phenolics varies dependent on pretreatments and how they may affect both enzymatic hydrolysis and fermentation.

In order to develop more efficient pretreatment or detoxification methods for improving the bioconversion performance, a better understanding of the effect of pretreatment-derived phenolics on enzymatic hydrolysis and fermentation is desirable.

Acid pretreatment-derived phenolics have strong inhibitory effects on cellulose hydrolysis and fermentation. During dilute acid (DA) pretreatment, lignin is subjected to depolymerization and repolymerization reactions, giving rise to various types of water-soluble phenolic compounds, such as vanillin, ferulic acid and p-coumaric acid $[11,12]$. Previous studies have shown that vanillin at a concentration of $10 \mathrm{mg} / \mathrm{mL}$ strongly decreased the cellulose hydrolysis by $26 \%$ compared to the control [13]. In addition, phenolics were also regarded as more toxic compounds towards fermenting microorganisms compared to other degradation products such as furan aldehydes and weak acids. Ezeji et al. reported that ferulic acid and $p$-coumaric acid at a concentration of $1 \mathrm{~g} / \mathrm{L}$ strongly inhibited the cell growth of Clostridium beijerinckii BA101 bacteria strain by up to $74 \%$ [14]. Adeboye et al. found that ferulic acid (1.8 mM) and $p$-coumaric acid $(9.7 \mathrm{mM})$ decreased cell growth of a Saccharomyces cerevisiae by up to $80 \%$ [15]. The strong toxicity of phenolics towards microorganisms might be due to their aromatic properties that make them more easily penetrate cell membranes, resulting in the damage of internal structures, the decrease in cell growth and the change of cell morphology [16].

Even though some studies have reported the effects of dilute acid (DA) pretreatment-derived phenolics, only a few studies focused on the inhibitory effect of phenolics derived from other pretreatments such as alkaline pretreatment (AL), ammonia fiber expansion (AFEX) and liquid hot water pretreatment (LHW) on enzymatic hydrolysis and fermentation. Although these pretreatments (AL, AFEX and LHW) effectively deconstruct lignocellulosic biomass, they applied different reaction mechanisms to generate phenolics from partial lignin degradation. For example, alkaline pretreatment using $\mathrm{NaOH}$ as the pretreatment agent results in the breakage of $\beta$-O-4 linkage, $\alpha$-ether linkage and demethylation via nucleophilic substitution [17], and thus it will give rise to a high proportion of phenolics with methyl group removed. During AFEX, ammonolytic cleavage of cell wall ester and ether linkages lead to the formation of acetamide and various phenolic amides [18]. For LHW, an elevated level of hydronium ions acted as an acid at high holding temperature, to promote the partial lignin depolymerization [19]. The degree of depolymerization of lignin by LHW was much lower than that from AL pretreatment. DA pretreatment catalyzes the degradation of lignin through acid catalysis mechanism, while a high level of lignin condensation tends to happen during the pretreatment process [12]. Because of the different reaction mechanisms of these pretreatments, it is expected that different pretreatment produces phenolics with various structures, which may show varied inhibitory effects on cellulose hydrolysis and fermentation. Moreover, the $\mathrm{pH}$ of AL, AFEX, LHW and DA ranges from high to low. Due to the $\mathrm{pH}$ variety during pretreatment, the potential lignin degradation reactions might be different, which will give rise to phenolics with different effects on enzymatic hydrolysis and fermentation. For 
example, Humpula et al. have reported the phenolics-rich hydrolysate from AFEX-pretreated corn stover inhibited enzymatic hydrolysis by around $20 \%$ [18]. In terms of fermentation, Kim et al. found that the effect of phenolics derived from mild alkaline treatment with aqueous ammonia solution was less inhibitory [20]. However, the effect of phenolics derived from different pretreatments on fermentation has not been well evaluated and compared, as most of the previous studies used pretreatment hydrolysate, which contained various soluble compounds, or phenolic model compounds that cannot represent the actual pretreatment-derived phenolics. To further understand the role of phenolics in impeding the production of cellulosic ethanol through hydrolysis and fermentation, more detailed studies are still in need to understand the phenolics-caused inhibition. Most importantly, it is necessary to know how pretreatment may affect the characteristics of phenolics and their inhibition on the overall bioconversion processes to produce cellulosic ethanol. This knowledge will be essentially helpful for the development of less "toxic" pretreatment or detoxification process for both hydrolysis and fermentation and the improvement of ethanol bioconversion performance.

The inhibitory effects of water-soluble phenolic compounds derived from AL, DA LHW and AFEX-pretreated corn stover on both enzymatic hydrolysis and sugar fermentation by Zymomonas mobilis 8b strain were systematically evaluated in this work. The structure characteristics of the phenolics were conducted by using LC-MS and FT-IR to elucidate the differences in the phenolics derived from different pretreatments. The effects of typical model phenolics compounds from pretreatment process on enzymatic hydrolysis and fermentation were also studied.

\section{Results and discussion}

Mass balance of water-soluble phenolic compounds (WPC) During pretreatment, various phenolics were generated from lignin and reported to be inhibitory toward enzymatic hydrolysis and fermentation [19, 21, 22]. In addition, the composition and structure of phenolics also significantly depended on the pretreatment conditions [23, 24]. In the present work, different pretreatments were conducted under optimum conditions, and then phenolics were extracted from pretreatment liquid stream through solvent extraction. Four pretreatments, including DA, LHW, AFEX and AL were selected to represent pretreatments at various $\mathrm{pH}$. Results showed that pretreatments had a great impact on the amount of WPC generated (Fig. 1). According to the composition analysis, it was found that more than $80 \%$ of the extractives from pretreatment liquid streams were WPC (Fig. 1).
Specifically, after pretreatment of $100 \mathrm{~g}$ corn stover, AL produced $5.9 \mathrm{~g}$ WPC, while DA released $3.3 \mathrm{~g}$ WPC. LHW and AFEX produced $1.6 \mathrm{~g}$ and $1.8 \mathrm{~g}$ WPC, respectively, which were much less compared with AL and DA. Although the WPC contained a minor amount of sugars and other degradation compounds (Additional file 1: Table S1), these compounds were present at low concentrations that would not affect enzymatic hydrolysis and fermentation $[9,12,25]$.

\section{The inhibitory effect of WPC on enzymatic hydrolysis}

The effect of WPC from each pretreatment on enzymatic efficiency of cellulose was evaluated under different concentrations (Fig. 2). With the increase of the WPC concentration, the glucose yield decreased significantly in enzymatic hydrolysis. When the concentration of WPC reached $6 \mathrm{~g} / \mathrm{L}$, the efficiencies of cellulose hydrolysis were decreased by $20 \%-40 \%$ as compared with the control, indicating that the WPC concentration had a great impact on the inhibitory effect. In addition, the degree of inhibition by WPC highly depended on pretreatments employed. Results showed that WPC at $2 \mathrm{~g} / \mathrm{L}$ derived from AFEX reduced the glucose yield by $13.8 \%$, while WPC at the same concentration derived from LHW, $\mathrm{AL}$ and DA showed no significant effect on enzymatic hydrolysis. When the WPC concentration increased to $6 \mathrm{~g} / \mathrm{L}$, WPC derived from AFEX decreased the glucose concentration by $34.6 \%$, while WPC, derived from $\mathrm{AL}$, DA and LHW reduced the glucose yield by $11.9 \%, 16.7 \%$ and $25.8 \%$, respectively. Interestingly, results indicated that the AFEX-WPC showed the strongest inhibitory on cellulose hydrolysis, followed by LHW-WPC, DA-WPC and AL-WPC.

To further confirm the observation in a realistic scenario, the influence of phenolics on enzymatic hydrolysis of alkaline pretreated corn stover (washed and containing both cellulose and hemicellulose) was evaluated at relatively high solid loading $(20 \% \mathrm{w} / \mathrm{w})$. In terms of the effect of phenolics on cellulose conversion, a similar trend was observed: AFEX-WPC showed the strongest inhibitory effect, followed by LHW-WPC, DA-WPC and AL-WPC (Additional file 1: Fig. S1). At 20\% solid loading of pretreated corn stover, AFEX-WPC at $6 \mathrm{~g} / \mathrm{L}$ reduced the glucose concentration from $105.1 \mathrm{~g} / \mathrm{L}$ to $79.9 \mathrm{~g} / \mathrm{L}$ (corresponding to $24.0 \%$ inhibition of enzymatic hydrolysis). Different from cellulase inhibition, phenolics derived from different pretreatment had similar inhibitory effects on xylose conversion (Additional file 1: Fig. S1). It could be possible that the inhibition mechanism of cellulase is different from that of xylanases or the inhibitory effect of WPC on xylanases was masked by strong sugar inhibition at high solid loading. 


\section{(1) AL-CS}

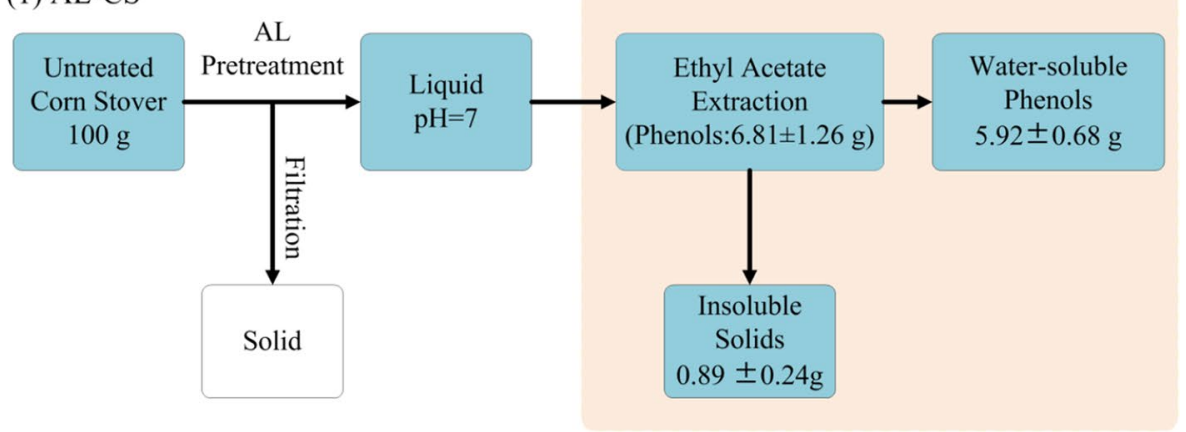

(2) DA-CS

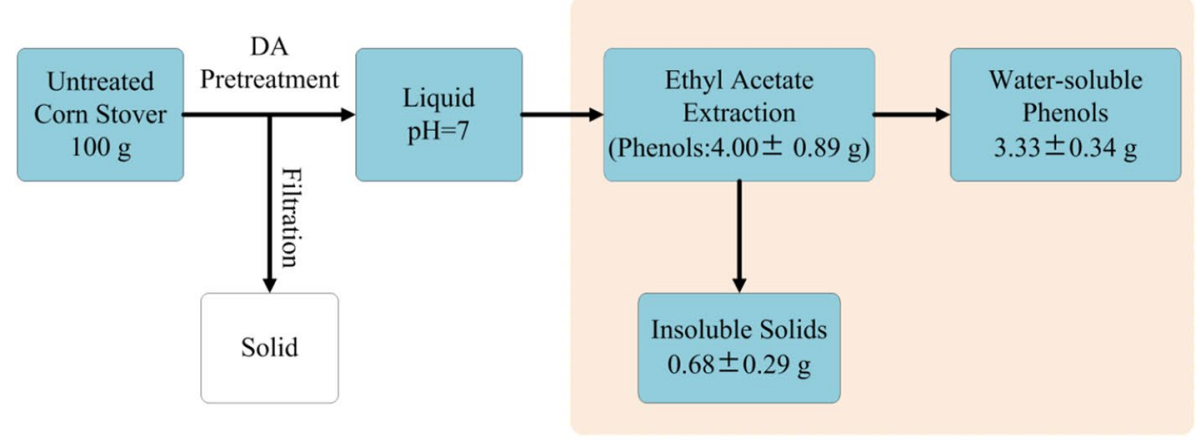

(3) LHW-CS

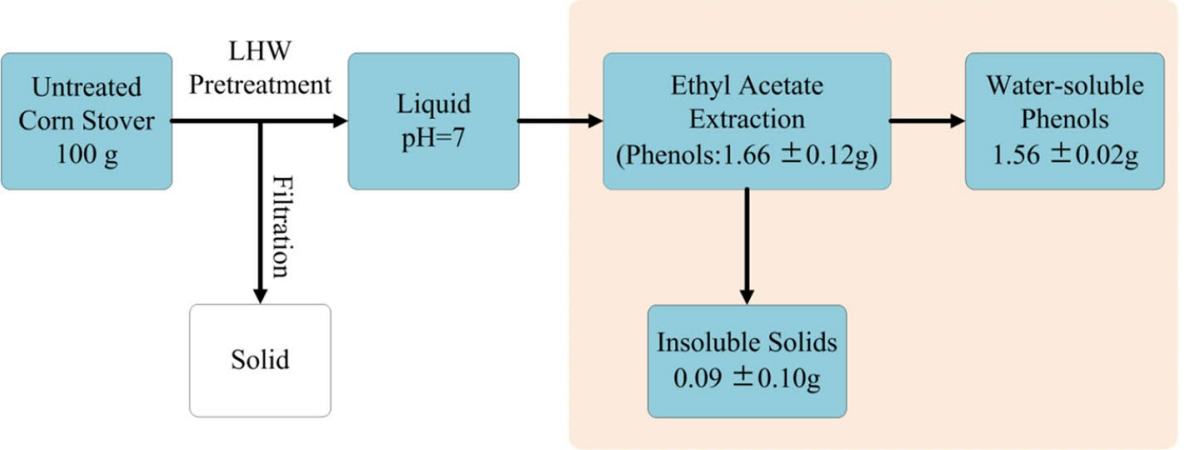

(4) AFEX-CS

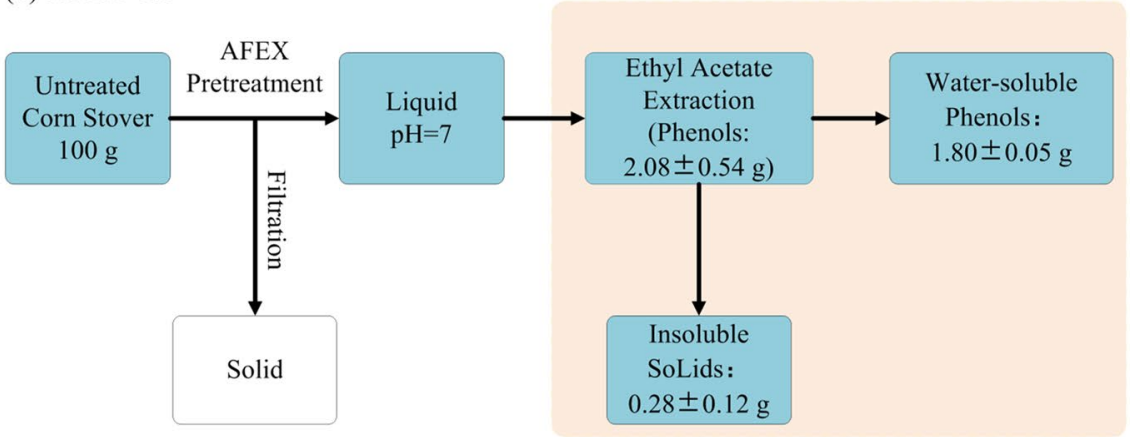

Fig. 1 Ethyl acetate extraction of phenolics from different pretreated corn stover. (1) AL-CS: alkali pretreated corn stover; (2) DA-CS: dilute acid pretreated corn stover; (3) LHW-CS: liquid hot water pretreated corn stover and (4) AFEX-CS: ammonia fiber expansion pretreated corn stover. Phenolics were determined according to Folin Ciocalteu assay, and vanillin was used as standard for this method to measure the phenolics content. The phenolics measurement was done in duplicate with the average values and standard deviations reported 

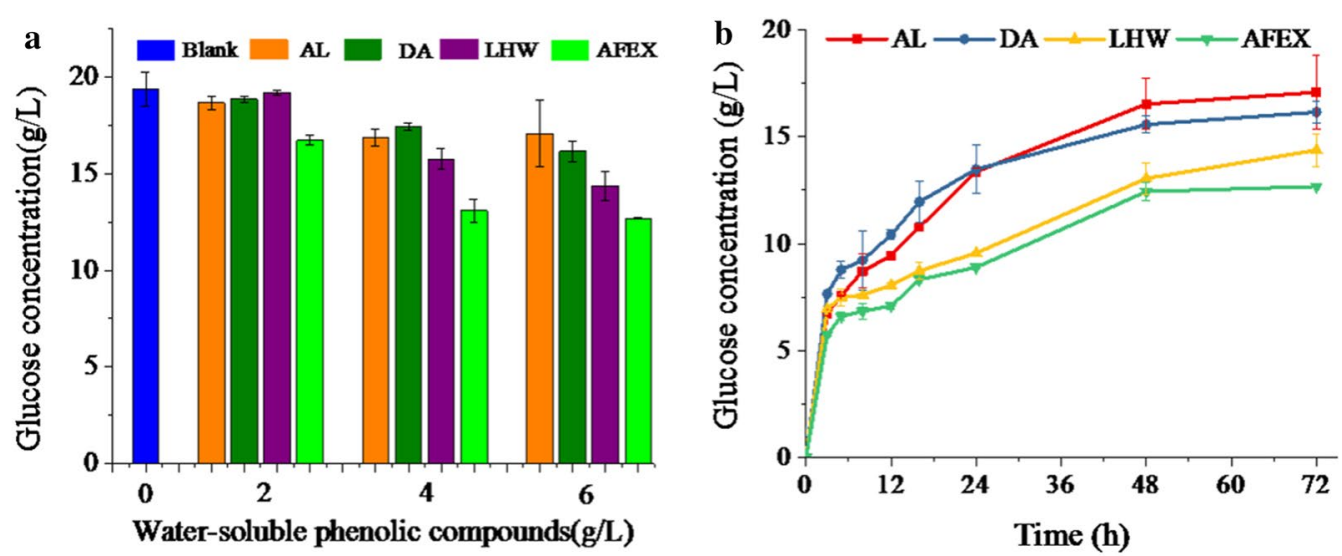

Fig. 2 Effect of water-soluble phenolic compounds (WPC) on enzymatic hydrolysis. a Enzymatic hydrolysis in the presence of $0 \mathrm{~g} / \mathrm{L}, 2 \mathrm{~g} / \mathrm{L}, 4 \mathrm{~g} / \mathrm{L}$ and $6 \mathrm{~g} / \mathrm{L}$ of WPC for $72 \mathrm{~h}$, at $50^{\circ} \mathrm{C}, 25 \mathrm{rpm} ; \boldsymbol{b}$ time course of enzymatic hydrolysis with $2 \mathrm{~g} / \mathrm{L} \mathrm{WPC}$ derived from each pretreatment

Previous studies have confirmed that DA and LHW derived phenolics had strong inhibitory compounds for cellulase enzymes $[11,19]$, however, few studies had reported the inhibitory effect of WPC derived by AFEX on cellulases. In the present study, although WPC derived from AFEX showed a stronger inhibitory effect on cellulases compared to other pretreatments, the total amount of phenolics released by AFEX was significantly lower than that generated from DA and AL. As shown in Fig. 1, AFEX generated $1.80 \mathrm{~g}$ WPC from $100 \mathrm{~g}$ corn stover, while AL and DA pretreatment released $5.92 \mathrm{~g}$ and $3.33 \mathrm{~g}$ WPC, respectively. With the consideration of the amount of WPC generated from each pretreatment, the overall inhibitory effect of WPC derived from AFEX towards enzymatic hydrolysis of cellulose was similar to that of DA-WPC and AL-WPC, while WPC derived from LHW showed the least inhibitory effect (Fig. 2). Therefore, these results showed that the inhibitory effects of WPC on the enzymatic hydrolysis depended on the concentration and pretreatment employed, and WPC derived from LHW exhibited less inhibitory effects as compared with other pretreatments.

\section{The inhibitory effect of WPC on fermentation}

The effect of WPC produced from each pretreatment on ethanol fermentation was also evaluated in the present study. Z. mobilis $8 \mathrm{~b}$ had been genetically modified to coferment glucose and xylose for ethanol production, and is featured with excellent industrial characteristics, such as low cell biomass formation, high ethanol yield and wide $\mathrm{pH}$ tolerance $[26,27]$. Therefore, it was selected to evaluate the inhibitory effect of WPC on fermentation. As shown in Fig. 3, the inhibitory effects of WPC were also dependent on the pretreatment employed. AL-WPC showed the strongest inhibitory effect on fermentation, followed by LHW-WPC, DA-WPC, and AFEX-WPC. The inhibitory effects of WPC were greatly different from those on enzymatic hydrolysis. With the presence of $4 \mathrm{~g} / \mathrm{L}$ WPC, sugar consumptions, cell growth and ethanol production were strongly inhibited by WPC derived from AL and LHW, while they were slightly inhibited by WPC derived from DA and AFEX. When the concentration increased to $6 \mathrm{~g} / \mathrm{L}$, DA-WPC exhibited almost complete inhibition of fermentation. Interestingly, AFEXWPC at $6 \mathrm{~g} / \mathrm{L}$ showed relatively low inhibitory effect on fermentation. All of the glucose and $38 \%$ of initial xylose were consumed after $120 \mathrm{~h}$ fermentation in the presence of AFEX-WPC, while less than $10 \%$ of initial glucose was consumed in the presence of $6 \mathrm{~g} / \mathrm{L} \mathrm{WPC} \mathrm{from} \mathrm{other} \mathrm{pre-}$ treatments. Growth and sugar fermentation of Z. mobilis 8 b were most strongly inhibited by AL-WPC (Fig. 3). The difference in the WPC inhibition on fermentation might be related to molecular size and structures of phenolics generated from each pretreatment [28].

WPC from each pretreatment also showed a stronger inhibitory effect on xylose consumption compared to glucose consumption (Fig. 3). Such effect was dependent on the concentration of WPC and became more obvious with the increase of WPC concentration. The fermentation time course in the presence of $2 \mathrm{~g} / \mathrm{L}$ WPC is shown in Fig. 4. Glucose/xylose consumption and ethanol production were rapid in the first $24 \mathrm{~h}$. At $2 \mathrm{~g} / \mathrm{L}, \mathrm{AL}-\mathrm{WPC}$ already rendered significant reduction on xylose consumption and cell growth (Fig. 4b, d) with $7.5 \mathrm{~g} / \mathrm{L}$ xylose left unfermented. In addition, the xylose consumption was sensitive to WPC, which showed a similar trend to the cell growth. Specifically, AL-derived WPC showed an obvious inhibitory effect on both the xylose consumption and cell growth at $2 \mathrm{~g} / \mathrm{L}$, while no obvious effect on glucose consumption was observed. These results suggested 

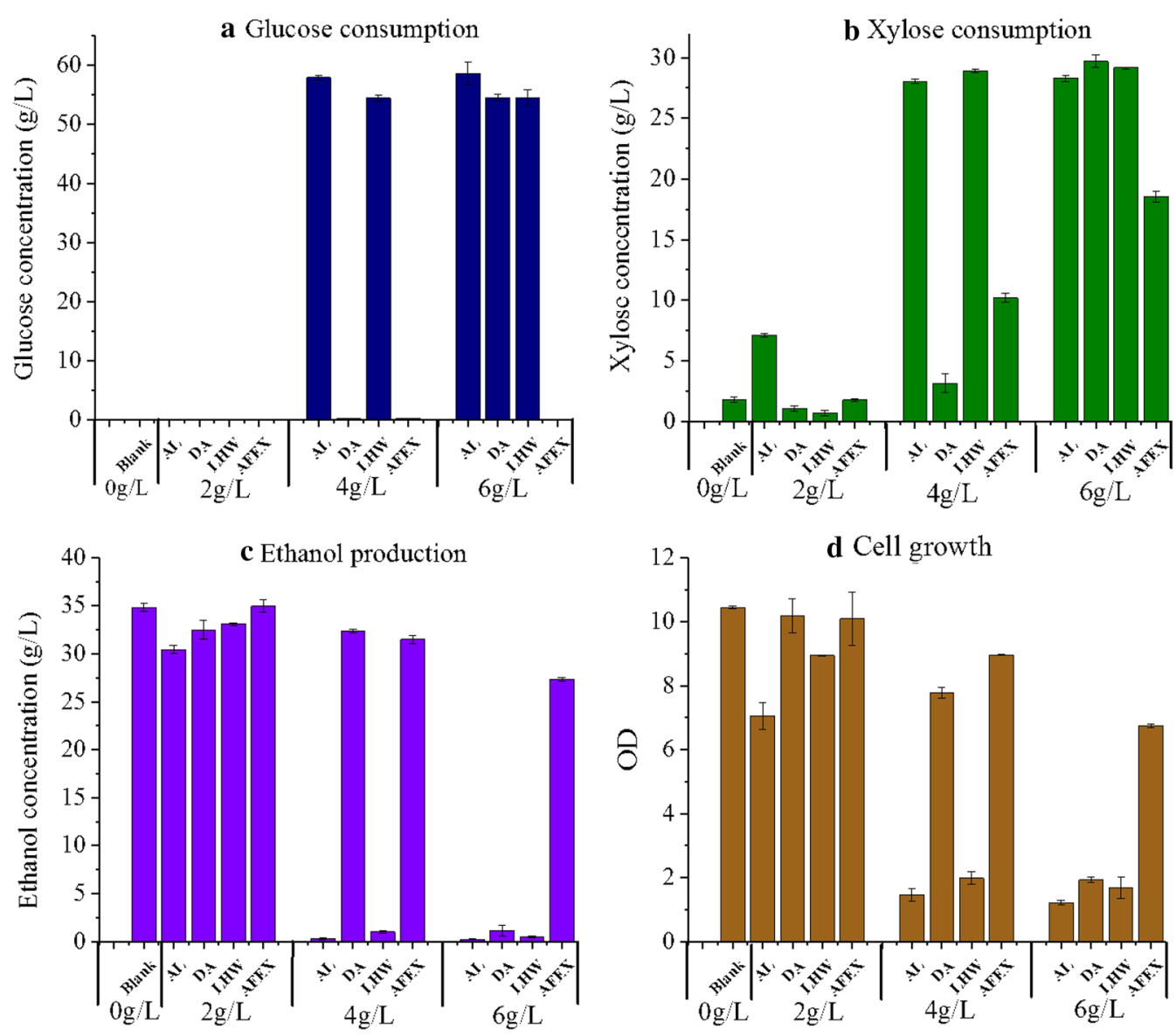

Fig. 3 Fermentation performance of $Z$. mobilis $8 \mathrm{~b}$ strain in the presence of $0 \mathrm{~g} / \mathrm{L}, 2 \mathrm{~g} / \mathrm{L}, 4 \mathrm{~g} / \mathrm{L}$ and $6 \mathrm{~g} / \mathrm{L}$ WPC derived from different pretreatments. a Residual glucose after $120 \mathrm{~h}$ fermentation; $\mathbf{b}$ residual xylose after $120 \mathrm{~h}$ fermentation; c ethanol titer after $120 \mathrm{~h}$ fermentation and; $\mathbf{d}$ cell growth. Fermentation was conducted in Erlenmeyer flasks $(8 \mathrm{~mL})$ at $\mathrm{pH} 6,30^{\circ} \mathrm{C}$ and $150 \mathrm{rpm}$

that the phenolics exhibited a stronger inhibitory effect on the growth of $Z$. mobilis $8 \mathrm{~b}$ strain and xylose consumption. Considering the significant inhibitory effect of phenolics on xylose consumption, it is desirable to promote strain improvement on xylose utilization, especially in the presence of pretreatment-derived phenolics.

\section{Characteristics of WPC}

The above-mentioned results suggested that WPC derived from different pretreatments had diverse inhibitory effects on enzymatic hydrolysis and fermentation. To investigate the potential inhibitory mechanism of WPC, the composition and structure characteristics of WPC derived from each pretreatment were evaluated. According to LC-MS analysis (Additional file 1: Table S2), ALWPC and AFEX-WPC contained a high percentage of $p$-coumaric acid and benzaldehyde. According to previous studies, $p$-coumaric acid was esterified and linked to hemicelluloses or lignin in grasses and it could be released through alkaline pretreatment; in addition, benzaldehyde was found to be the major product generated from breakage of the $\beta-\mathrm{O}-4$ model compound via nucleophilic substitution under basic hydrothermal conditions $[29,30]$. Different from AL-CS, feruloylamide was detected in the WPC from AFEX-CS, which is consistent with previous observation [31]. Feruloylamide has been considered as a major ammoniated lignin degradation product produced by ammonolysis of polyphenolic esters. For the WPC from LHW-CS, the percentage of $p$-coumaric acid reduced and the percentage of benzoic acid increased compared to AL and AFEX, suggesting the degradation of esterified $p$-coumaric acid was limited under hydrothermal conditions. For the WPC from DA-CS, $p$-coumaric acid was the predominant product, with a relatively high amount of benzaldehyde. According to previous studies, benzaldehyde was suggested to be the product derived from the acidolysis of lignin reported by previous studies [11].

To comprehensively understand the characteristics of WPC, FT-IR was employed for functional group analysis 

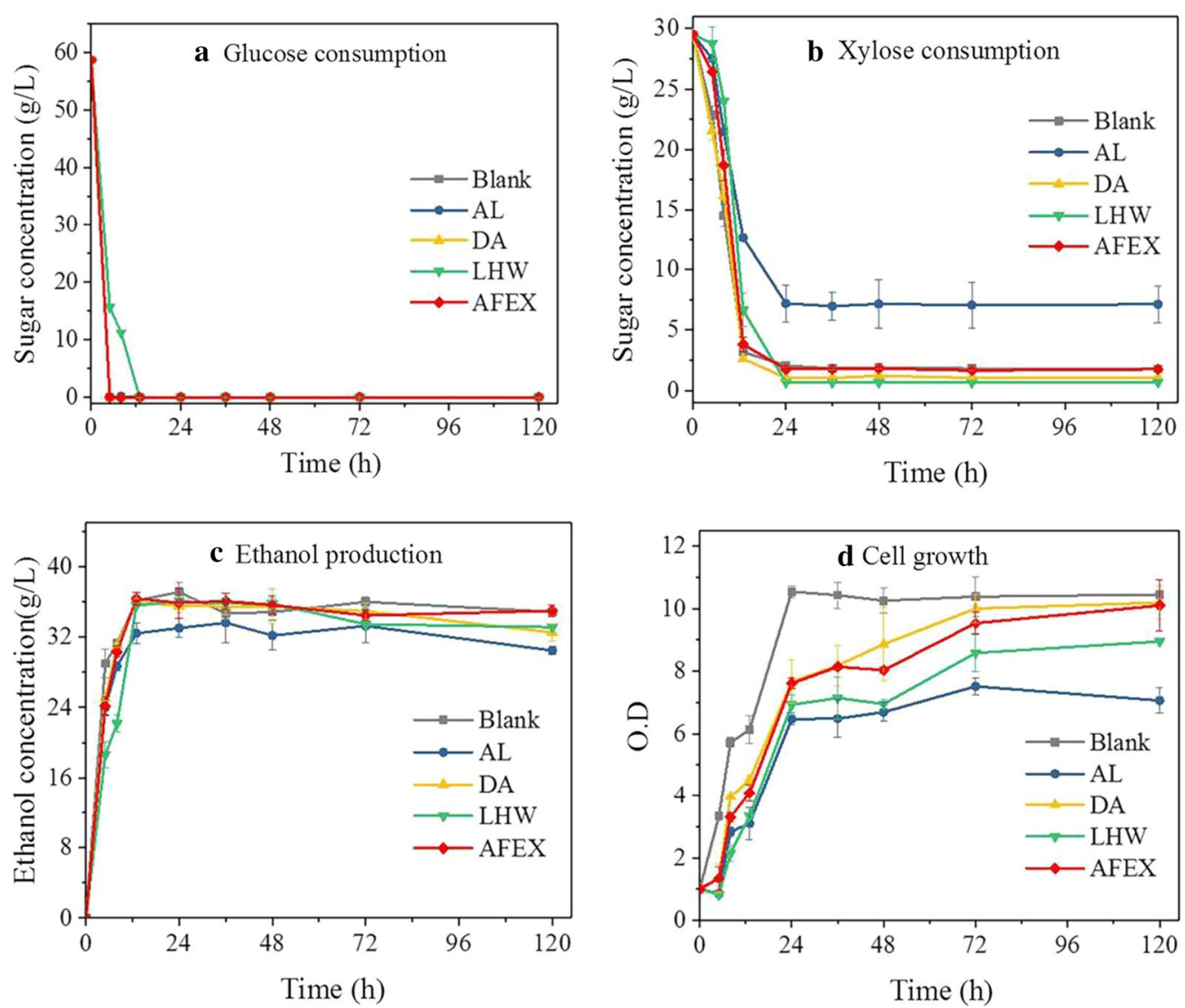

Fig. 4 Fermentation performance of Z. mobilis $8 \mathrm{~b}$ strain in the presence of $2 \mathrm{~g} / \mathrm{L}$ WPC derived from different pretreatment. a Glucose consumption; b xylose consumption; c ethanol production and $\mathbf{d}$ cell growth. Blank: no water-soluble phenol. AL alkali pretreatment, DA dilute acid pretreatment, LHW liquid hot water pretreatment, AFEX ammonia fiber expansion (AFEX) pretreatment. Fermentation was conducted in Erlenmeyer flasks (8 $\mathrm{mL}$ ) at $\mathrm{pH} 4.8,30^{\circ} \mathrm{C}$ and $150 \mathrm{rpm}$ with inoculum at $1\left(\mathrm{OD}_{600}\right)$

of phenolics to provide a general outlook of the major structure properties of WPC (Table 1 and Fig. 5). Results showed that the four types of WPC exhibited similar adsorption spectrum at 3300, 2923, $1509 \mathrm{~cm}^{-1}$, which could be assigned to the stretching vibrations of aromatic hydroxyl groups, $\mathrm{C}-\mathrm{H}$ stretching vibrations from methyl and methylene residue and stretch of aromatic rings, respectively [32]. As the strong peak at $1509 \mathrm{~cm}^{-1}$ shared by those four WPC suggested the presence of aromatic rings, this peak could be used as the reference peak to semi-quantitatively and analyze the relative amount of different functional groups [33, 34].

In the spectrum of WPC derived from AFEX (Table 1 and Fig. 5), a high-intensity peak at $1662 \mathrm{~cm}^{-1}$ displayed, which could be attributed to the presence of $\mathrm{CONH}_{2}$ in amide groups [36]. This is consistent with the LC-MS result. In addition, previous study had confirmed that the phenolics in AFEX-pretreated biomass contained a large amount of amides, such as acetamide, ferulamide and coumaroylamide due to ammonolysis of lignin by using ultra-high performance liquid chromatographymass spectrometry (UHPLC-MS) [31]. The shoulder peak at $1662 \mathrm{~cm}^{-1}$ in the spectrum of DA-WPC, LHWWPC and AL-WPC suggests the amount of free $-\mathrm{C}=\mathrm{O}$ or CONH2 $[34,35]$. Interestingly, as shown in Table 2, the ratio of Abs1662 to Abs1509 followed the order: $R_{A F E X}>R_{L H W}>R_{D A}>R_{A L}$, which was consistent with the degree of inhibition of cellulose hydrolysis by the relevant WPC. It had been reported that the $-\mathrm{C}=\mathrm{O}$ or $\mathrm{CONH}_{2}$ served as strong dipole and could strongly interact with cellulases to inhibit cellulase activity [36, 37]. Thus, the higher amount of $-\mathrm{C}=\mathrm{O}$ or $\mathrm{CONH}_{2}$ might result in stronger binding between phenolics and enzymes and reduction of enzymatic hydrolysis performance. Previous studies showed the contribution of $-\mathrm{C}=\mathrm{O}$ to phenolic inhibition on cellulase, however, whether $\mathrm{CONH}_{2}$ is responsible for the cellulase inhibition remains unknown. Based on the correlation observed above, it is likely that the CONH2 group in WPC generated from AFEX also contributed to the cellulase inhibition. 
Table 1 FT-IR analysis of WPC derived from AL, DA, LHW and AFEX pretreatment

\begin{tabular}{|c|c|c|c|c|c|c|}
\hline \multirow[t]{2}{*}{ Wavenumber/cm ${ }^{-1}$} & \multirow[t]{2}{*}{ Origin } & \multirow{2}{*}{$\begin{array}{l}\text { Attribution and description of FT-IR } \\
\text { absorption }\end{array}$} & \multicolumn{4}{|c|}{ Wavenumber $\mathrm{cm}^{-1}$} \\
\hline & & & AL-WPC & DA-WPC & LHW-WPC & AFEX-WPC \\
\hline $3200-3400$ & $\mathrm{O}-\mathrm{H}$ & $\begin{array}{l}\text { Wide absorption band, aliphatic and aromatic } \\
\mathrm{O}-\mathrm{H} \text { stretching }\end{array}$ & 3308 & 3308 & 3308 & 3308 \\
\hline $3350-3200$ & $\mathrm{CONH}_{2}$ & [36], N-H absorption, double peak & NA & NA & NA & 3210 and 3348 \\
\hline 2908-2992 & $\mathrm{CH}_{3}, \mathrm{CH}_{2}$ & Aliphatic and aromatic $\mathrm{O}-\mathrm{H}$ stretching & 2925 & 2925 & 2925 & 2939 \\
\hline $1650-1660$ & $\mathrm{CONH}, \mathrm{CONH}_{2}$ & $\mathrm{C}=\mathrm{O}$ stretching vibration & NA & NA & NA & 1654 \\
\hline $1610-1550$ and $1420-1300$ & $\mathrm{COO}-$ & Carboxylate & $1567(1410)$ & $1567(1410)$ & $1567(1410)$ & $1567(1410)$ \\
\hline $1600(1450)$ & $\operatorname{Ar}$ & Aromatic hydrocarbon & $1600(1450)$ & $1600(1450)$ & $1600(1450)$ & $1600(1450)$ \\
\hline $1507-1515$ & & Aromatic skeletal vibration; $\mathrm{G}>\mathrm{S}$ & 1509 & 1509 & 1509 & 1509 \\
\hline 1267 & $\mathrm{O}-, \mathrm{CO}-\mathrm{O}$ & $\begin{array}{l}\text { G ring and acyl-oxygen bond } \mathrm{CO}-\mathrm{O} \text { stretching } \\
\text { vibration }\end{array}$ & NA & NA & 1267 & NA \\
\hline $1237-1241$ & $\mathrm{OCH}_{3}$ & $\begin{array}{l}\text { Methoxyl, C-C and C-O stretching vibration; } \mathrm{C}] \\
\mathrm{O} \text { stretching vibration (condensed } \mathrm{G}>\text { etheri- } \\
\text { fied G) }\end{array}$ & 1235 & NA & 1239 & 1236 \\
\hline $1168-1170$ & $\mathrm{COOC}$ & $\begin{array}{l}\text { HGS characteristics; conjugated ester-based } \\
\mathrm{C}=\mathrm{O} \text { stretching vibration }\end{array}$ & NA & NA & NA & 1169 \\
\hline $1126-1127$ & $\mathrm{C}-\mathrm{H}, \mathrm{C}-\mathrm{O}$ & $\begin{array}{l}\text { C-H aromatic-plane bending vibration, char- } \\
\text { acteristics of S ring; coincide with secondary } \\
\text { alcohol C-O stretching vibration }\end{array}$ & 1127 & 1126 & 1126 & 1127 \\
\hline $1035-1045$ & $\mathrm{C}-\mathrm{H}, \mathrm{C}-\mathrm{O}$ & $\begin{array}{l}\mathrm{C}-\mathrm{H} \text { aromatic in-plane bending vibration, } \mathrm{G}>\mathrm{S} \text {; } \\
\text { primary alcohol } \mathrm{C}-\mathrm{O} \text { stretching vibration }\end{array}$ & 1042 & NA & 1042 & 1038 \\
\hline $834-835$ & $\mathrm{C}-\mathrm{H}$ & $\mathrm{S}$ ring $\mathrm{C}-\mathrm{H}$ out-of-plane bending vibration & 835 & NA & NA & 835 \\
\hline
\end{tabular}

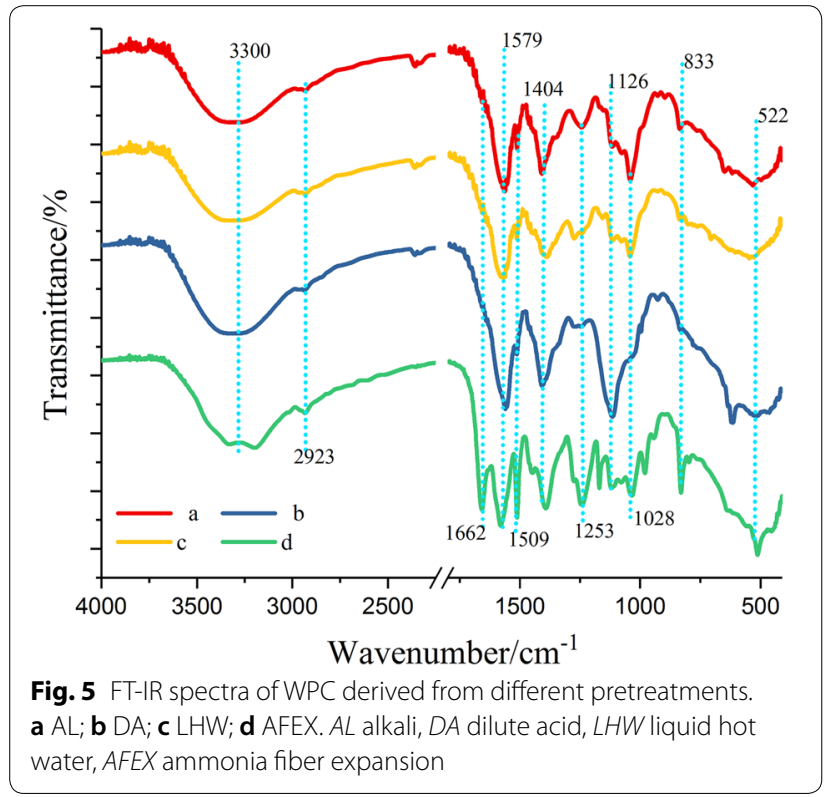

In terms of the effect of WPC derived from each pretreatment on fermentation, AL-WPC showed the strongest inhibitory effect likely due to the high amount of phenolic aldehyde, which had been confirmed as inhibitors of fermenting microorganisms [38]. Considering the
Table 2 Relevant FT-IR absorption bands and related absorbance ratios (other's absorbance/1509 $\mathrm{cm}^{-1 / s}$ absorbance) of WPC

\begin{tabular}{lllll}
\hline Band $\left(\mathbf{c m}^{\mathbf{- 1}}\right)$ & AL-WPC & DA-WPC & LHW-WPC & AFEX-WPC \\
\hline \multicolumn{2}{l}{ Baseline corrected band intensities } & & \\
3300 & 0.69 & 0.81 & 0.80 & 0.45 \\
1662 & 0.38 & 0.44 & 0.60 & 1.00 \\
1579 & 1.77 & 1.69 & 2.00 & 1.21 \\
1509 & 1.00 & 1.00 & 1.00 & 1.00 \\
1404 & 1.54 & 1.56 & 1.50 & 1.00 \\
1253 & 0.77 & 0.75 & 1.00 & 0.90 \\
1168 & 0.54 & 1.19 & 0.70 & 0.79 \\
1126 & 1.00 & 2.00 & 1.00 & 0.76 \\
1028 & 1.46 & 1.13 & 1.30 & 0.86 \\
833 & 0.85 & 0.75 & 0.80 & 0.83 \\
\hline
\end{tabular}

structural characteristics of phenolics, it was reported that the amide group in phenolics lowered the toxicity of phenolics towards Saccharomyces cerevisiae 424A (LNH-ST) [39]. Therefore, the phenolic amides generated from AFEX pretreatment might have contributed to the reduced inhibition of fermentation by $Z$. mobilis $8 \mathrm{~b}$, as compared with other WPC generated from AL, DA, and LHW pretreatment. 


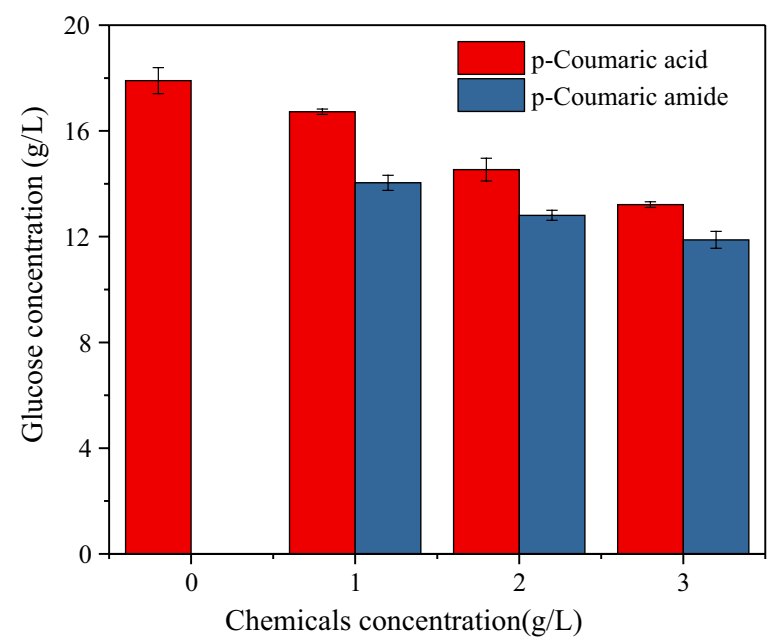

Fig. 6 Effect of $p$-coumaric acid and $p$-coumaric amide on enzymatic hydrolysis of Avicel. Enzymatic hydrolysis with different concentrations of $p$-coumaric acid and $p$-coumaric amide was performed for $72 \mathrm{~h}$, at $50^{\circ} \mathrm{C}, 25 \mathrm{rpm}$

\section{Effect of phenolics with acid and amide group on enzymatic hydrolysis and fermentation}

The above results showed that AFEX-derived phenolics exhibited a stronger inhibitory effect on enzymatic hydrolysis but less inhibitory effect on fermentation. Based on the structure analysis, it was hypothesized that phenolic amide might contribute to such observation. To further verify the hypothesis, model phenolics were used as inhibitors for enzymatic hydrolysis and fermentation. $p$-Courmaric amide and its corresponding acid were selected as typical phenolic compounds. Figure 6 shows that the glucose release in the presence of $p$-coumaric acid and $p$-coumaric amide decreased gradually with the increase of phenolic concentration. Glucose release was significantly inhibited by $p$-coumaric amide, as glucose concentration was reduced by $21.6 \%-33.6 \%$ in the presence of 1.0-3.0 g/L $p$-coumaric amide as compared with the reduction of $6.6 \%-26.2 \%$ in the presence of 1.0-3.0 g/L $p$-coumaric acid. These results suggested that phenolics with amide groups might have a stronger inhibitory effect compared with phenolics with acidic groups.

To further study why AFEX-derived phenolics showed low inhibitory effect on fermentation by $Z$. mobilis $8 \mathrm{~b}$, the effects of model phenolics ( $p$-coumaric acid and $p$-coumaric amide) on fermentation were studied. As expected, $p$-coumaric amide had a lower inhibitory effect on fermentation as compared with $p$-coumaric acid (Fig. 7). With increase of phenolics concentration, $p$-coumaric acid at $3 \mathrm{~g} / \mathrm{L}$ significantly decreased the ethanol concentration by $95.2 \%$, while $p$-coumaric amide at $3 \mathrm{~g} / \mathrm{L}$

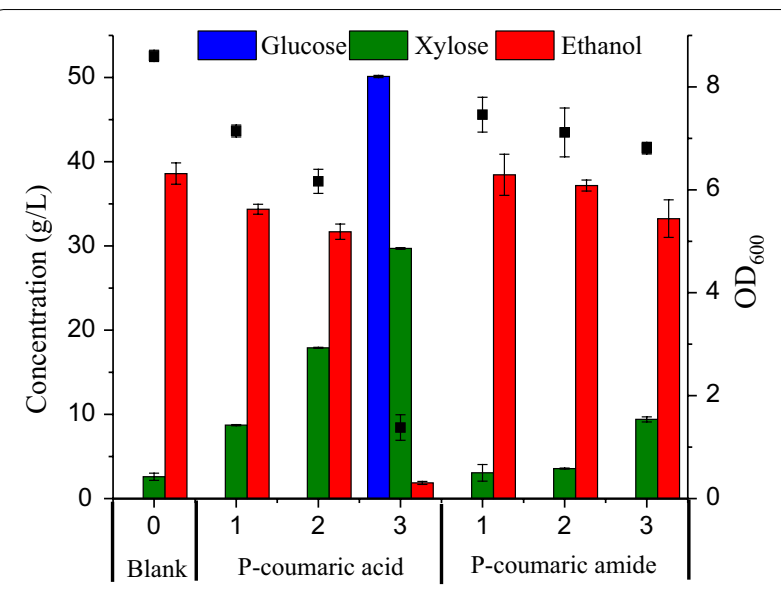

Fig. 7 Fermentation performance of Z. mobilis $8 \mathrm{~b}$ strain in the presence of $0 \mathrm{~g} / \mathrm{L}, 1 \mathrm{~g} / \mathrm{L}, 2 \mathrm{~g} / \mathrm{L}$ and $3 \mathrm{~g} / \mathrm{L} p$-coumaric acid or $p$-coumaric amide. Fermentation was conducted in Erlenmeyer flasks at $\mathrm{pH} 6,30^{\circ} \mathrm{C}$ and $150 \mathrm{rpm}$ for $120 \mathrm{~h}$. Medium containing $60 \mathrm{~g} / \mathrm{L}$ glucose, $30 \mathrm{~g} / \mathrm{L}$ xylose, $5 \mathrm{~g} / \mathrm{L}$ yeast extract, $10 \mathrm{~g} / \mathrm{L}$ tryptone was used for fermentation only slightly reduced the ethanol concentration by $13.9 \%$. The $p$-coumaric acid at $3 \mathrm{~g} / \mathrm{L}$ significantly decreased both glucose and xylose consumption by $Z$. mobilis $8 \mathrm{~b}$ strain, while $p$-coumaric amide only slightly reduced the xylose consumption (Fig. 7). The reduced sugar consumption was likely associated with the low cell growth rate, which is inhibited by the phenolics. For example, after $120 \mathrm{~h}$ fermentation, the $\mathrm{OD}_{600}$ only slightly went up to 2 in the presence of $3 \mathrm{~g} / \mathrm{L} p$-coumaric acid, while it reached around 7 in the presence of $3 \mathrm{~g} / \mathrm{L} p$-coumaric amide (Fig. 7). The result suggested the amide group of phenolics might have reduced inhibitory effect on fermentation. Therefore, these results indicated that the presence of high percentages of phenolics with amide groups in WPC derived from AFEX might contribute to their lower inhibitory effects on fermentation by $Z$. mobilis $8 \mathrm{~b}$ strain, compared with other WPC.

\section{Conclusions}

Results showed that the inhibitory effect of WPC on enzymatic hydrolysis and fermentation was greatly dependent on the WPC concentration and the pretreatment employed. AL pretreatment released the most quantity of phenolics, followed by DA, AFEX and LHW pretreatment. At the same phenolics concentration, the inhibitory effect of phenolics on enzymatic hydrolysis and fermentation varied significantly. The inhibitory effect of WPC on enzymatic hydrolysis followed the order: AFEX $>\mathrm{LHW}>\mathrm{DA}>\mathrm{AL}$, while the inhibitory effect of WPC on $Z$. mobilis $8 \mathrm{~b}$ fermentation followed the order: $\mathrm{AL}>\mathrm{LHW}>\mathrm{DA}>\mathrm{AFEX}$. Based on the 
characteristics of WPC, the strong inhibitory effect of AFEX-WPC on enzymatic hydrolysis and its low inhibitory effect on fermentation was likely related with the presence of phenolic amides. The strong inhibitory effect AL-WPC on fermentation was likely due to the high content of monomeric phenolic aldehydes. As both phenolic concentration and structural characteristics affected their inhibitory effects, the inhibitory effect of phenolics derived from AFEX on actual enzymatic hydrolysis of lignocellulosic biomass would be lower due to their low content in the AFEX-pretreated biomass. Overall, the present study provides a new insight into the phenolicscaused inhibition on both hydrolysis and fermentation, which could guide the design of effective pretreatment with low toxicity and efficient detoxification strategies that aim to selectively remove or modify the degradation products prior to enzyme hydrolysis and microbial fermentation.

\section{Materials and methods Biomass and enzyme}

Corn stover biomass used in this study was harvested and air-dried in 2017 at Lianyungang, Jiangsu province, China. The corn stover was knife milled using a laboratory mill with $4 \mathrm{~mm}$ particle size interior sieve. The raw corn stover consists of $37.2 \pm 0.7 \%$ glucan, $19.2 \pm 0.0 \%$ xylan, $19.5 \pm 0.1 \%$ Klason lignin, and $3.9 \pm 0.5 \%$ ash. The corn stover biomass was then stored in plastic containers at $4{ }^{\circ} \mathrm{C}$ until further use. Cellulase $(60 \mathrm{mg}$ protein $/ \mathrm{mL}$ enzyme preparation) was generously provided by Qingdao Vland Biotech Co., Ltd.

\section{Biomass pretreatment}

AL pretreatment was performed in an autoclave with $10 \%(\mathrm{w} / \mathrm{w})$ solid loading, $2 \%(\mathrm{w} / \mathrm{w}) \mathrm{NaOH}$, at $121^{\circ} \mathrm{C}$ for $20 \mathrm{~min}$ [40]. DA pretreatment was carried out in a $2-\mathrm{L}$ high pressure reactor. The reactor containing $10 \%(\mathrm{w} / \mathrm{w})$ dry weight and $1 \%(\mathrm{w} / \mathrm{w})$ of sulfuric acid was heated to $160{ }^{\circ} \mathrm{C}$ and maintained for $10 \mathrm{~min}$ [40]. LHW pretreatment was performed at $200{ }^{\circ} \mathrm{C}$ for 5 min with $10 \%(w / w)$ solid loading. After AL, DA and LHW pretreatment, the slurry (liquid stream and solid loading) was allowed to cool down to room temperature and were then centrifuged at 10,000 rpm for $10 \mathrm{~min}$ to obtain pretreatment liquid stream. AFEX pretreatment in this work was performed in a 1-L reactor (Anhui Kemi Machinery Technology Co., LTD). AFEX pretreatment conditions were $120^{\circ} \mathrm{C}$ for $30 \mathrm{~min}$ at $60 \%$ moisture with the ratio of anhydrous ammonia to biomass (dry weight) equal to 1:1. After the treatment, the pretreated corn stover biomass was placed in a fume hood to remove residual ammonia, followed by adding $300 \mathrm{~mL}$ deionized water. After mixing, the slurry was centrifuged at 10,000 rpm for $10 \mathrm{~min}$ to separate pretreatment liquid stream. In all analyses above, pretreatment liquid stream (PLS) was neutralized to $\mathrm{pH} 7$ and then subjected to compositional analysis.

\section{Extraction of water-soluble phenolic compounds (WPC) from PLS}

To study the effect of WPC, ethyl acetate extraction was performed to extract phenolics from pretreatment biomass. This method has been commonly used in previous studies to extract phenolics from various natural resources $[31,41]$. The $\mathrm{pH}$ of PLS was adjusted to $\mathrm{pH} 7$ by $0.1 \mathrm{M}$ of $\mathrm{NaOH}$ or $\mathrm{HCl}$ to protonate the phenolic acids and other aromatic components of the mixture so as to increase their solubility in ethyl acetate. Then, one volume of PLS was mixed with three volumes of ethyl acetate, and allowed to sit for $30 \mathrm{~min}$ for phase separation. Subsequently, the top ethyl acetate phase was collected and three volumes of fresh ethyl acetate were added into the bottom water phase for another round of extraction. The extraction was repeated three times and the collected ethyl acetate phase was concentrated through a rotary evaporator. After evaporation, the concentrated phenolics fraction was placed in fume hood for $48 \mathrm{~h}$ to remove residual solvent and it was then further freeze-dried to remove residual water. The freeze-dried phenolics was dissolved in deionized water $(200 \mathrm{~mL})$ at $50{ }^{\circ} \mathrm{C}$, and centrifuged at 10,000 rpm for $10 \mathrm{~min}$. The WPC was dried at $105^{\circ} \mathrm{C}$ for $5 \mathrm{~h}$, which was further used for mass balance analysis. The WPC was concentrated through a freeze drier, which was further used for composition analysis, mass balances, enzymatic hydrolysis and fermentation.

\section{Synthesis of $p$-coumaric amide}

$p$-Coumaric amide was synthesized according to a reported method [42]. Specifically, $20 \mathrm{~g} p$-coumaric acid and $150 \mathrm{~mL}$ ethanol was added to $250 \mathrm{~mL}$ round-bottom flask equipped with a magnetic stir bar. $10 \mathrm{~mL}$ acetyl chloride was added and stirred at room temperature for $12 \mathrm{~h}$. Ethanol was removed in a rotary evaporator at $50^{\circ} \mathrm{C}$ to obtain the substrate. $10 \mathrm{~mL}$ of the substrate was transferred to heavy-wall long flask containing $40 \mathrm{~mL}$ concentrated ammonium hydroxide with a magnetic stir bar and sealed with a polytetrafluoroethylene cap. The sealed flask was incubated at $95^{\circ} \mathrm{C}$ in a heating oil bath covered for $12 \mathrm{~h}$. The flask was cooled and then left open for $\sim 8 \mathrm{~h}$ in a hood to allow evaporation of ammonium hydroxide. Under vacuum on a glass filter, the precipitated products (Containing $p$-coumaric amide) were collected. The purity of the products was analyzed by silica gel TLC developed with $4 \%$ methanol in chloroform. Only preparations exceeding 95\% purity were used for further experiments. 


\section{Enzymatic hydrolysis}

To evaluate the effects of inhibitors from each pretreatment on enzymatic hydrolysis, Avicel (Purchased from sigma company) was enzymatically hydrolyzed using commercial cellulase or xylanase mixture at $2 \% \mathrm{w} / \mathrm{w}$ dry weight loading $\left(\mathrm{pH} 4.8,50{ }^{\circ} \mathrm{C}\right)$ using a vertical rotator $(25 \mathrm{rpm})$. The hydrolysis was carried out at $20 \mathrm{mg}$ protein/g glucan loading with addition of $0 \mathrm{~g} / \mathrm{L}, 2 \mathrm{~g} / \mathrm{L}$, $4 \mathrm{~g} / \mathrm{L}, 6 \mathrm{~g} / \mathrm{L}$ WPC derived from each pretreatment, and the $\mathrm{pH}$ was maintained at 4.8 with $50 \mathrm{mM}$ citrate buffer. After hydrolysis, monomeric glucose and xylose concentrations of the liquid samples were determined by HPLC as described previously $[40,43]$.

\section{Fermentation}

Medium containing $60 \mathrm{~g} / \mathrm{L}$ glucose, $30 \mathrm{~g} / \mathrm{L}$ xylose, $5 \mathrm{~g} / \mathrm{L}$ yeast extract, $10 \mathrm{~g} / \mathrm{L}$ tryptone and $0 \mathrm{~g} / \mathrm{L}, 2 \mathrm{~g} / \mathrm{L}, 4 \mathrm{~g} / \mathrm{L}$, $6 \mathrm{~g} / \mathrm{L}$ WPC from each pretreatment was used as substrate to evaluate the effects of inhibitors on fermentation by a recombinant $Z$. mobilis 8 b strain, which can consume both glucose and xylose. Fermentation was carried out in a $10-\mathrm{mL}$ flask with a total reaction volume of $8 \mathrm{~mL}$ and initiated by inoculating $Z$. mobilis $8 \mathrm{~b}$ strain to reach $\mathrm{OD}_{600}$ of 1.0. The concentrations of glucose, xylose and ethanol were determined by HPLC [27].

\section{Analysis methods}

Biomass composition was analyzed according to NREL methods [44]. The concentrations of glucose, acetic acid, ethanol, HMF and furfural were determined using a Shimadzu HPLC system equipped with an Aminex HPX$87 \mathrm{H}$ column maintained at $60^{\circ} \mathrm{C}$ and Shimadzu refractive index detector (RID). $5 \mathrm{mM}$ sulfuric acid was used as an eluent at $0.6 \mathrm{~mL} / \mathrm{min}$ and the injection volume was $15 \mu \mathrm{L}$ $[40,45]$.

The total phenol concentrations were analyzed through Folin-Ciocalteu assay. In detail, $100 \mu \mathrm{L}$ sample was added into a glass tube and then mixed with $3 \mathrm{~mL}$ of water and $250 \mu \mathrm{L}$ Folin-Ciocalteu reagent. After $5 \mathrm{~min}$, $750 \mu \mathrm{L} \mathrm{Na}{ }_{2} \mathrm{CO}_{3}$ solution $(20 \%, \mathrm{w} / \mathrm{w})$ and $900 \mu \mathrm{L}$ water were then added to bring the volume to $5 \mathrm{~mL}$. The tube was incubated at $22{ }^{\circ} \mathrm{C}$ for $2 \mathrm{~h}$. The concentration of total phenol was then determined by measuring the absorbance at $760 \mathrm{~nm}[22,46]$.

LC-MS analysis of WPC was conducted using a Sciex 4600 Triple TOF mass spectrometer, Shimadzu column oven and CTC PAL auto-sampler, and was operated using electrospray ionization. Ultimate XB-C18 column $(2.1 \times 100 \mathrm{~mm}, 3 \mu \mathrm{m}$ particles $)$ was used together with deionized water containing $0.1 \%$ of formic acid (mobile phase A), CAN (mobile phase B) and column temperature held at $40{ }^{\circ} \mathrm{C}$. The gradient for analysis of the extract was as follows: $5 \% \mathrm{~B}$ until $2 \mathrm{~min}$, change from $5 \%$ to $70 \% \mathrm{~B}$ in $13 \mathrm{~min}$, from $70 \%$ to $90 \% \mathrm{~B}$ in $5 \mathrm{~min}$, from $90 \%$ to $5 \%$ B in 5 min and constant $5 \%$ B Until the end. The flow rate was constant at $0.4 \mathrm{~mL} / \mathrm{min}$ and the injected volume was $10 \mu \mathrm{L}$ [31].

Fourier transform infrared (FT-IR) spectra of WPC were obtained by a reported procedure [22]. Twenty scans for each sample were taken with a resolution of $2 \mathrm{~cm}^{-1}$ ranging from 400 to $4000 \mathrm{~cm}^{-1}$. The sample was prepared using the method of agate mortar crush before scanning.

\section{Supplementary information}

Supplementary information accompanies this paper at https://doi. org/10.1186/s13068-020-01686-z.

Additional file 1. Additional figures and tables.

\section{Abbreviations}

WPC: Water-soluble phenolic compounds; DA: Dilute acid; AL: Alkaline pretreatment; AFEX: Ammonia fiber expansion; LHW: Liquid hot water pretreatment; PLS: Pretreatment liquid stream; BSTFA: N,O-Bis(trimethylsilyl)trifluoroacetamide containing 1\% trimethylchlorosilane; GC-MS: Gas chromatography-mass spectrometer; FT-IR: Fourier transform infrared; HPLC: High performance liquid chromatography; Z. mobilis 8b strain: Zymomonas mobilis 8b strain.

\section{Acknowledgements}

This work was financially supported by National Key R\&D Program of China (Grant No. 2016YFE0105400), Natural Science Foundation of Jiangsu Province (Grant No. BK20170037 \& BK20170832), National Natural Science Foundation of China (Grant No. 21606132\&21908111), the Fundamental Research Funds for the Central Universities (Grant No. 30916011202 and Grant No. 30919011215), the Foundation of Jiangsu Specially Appointed Professor and the Foundation of Jiangsu Innovative and Entrepreneurial Doctors. The authors thank Prof. Qiang Zhang from Nanjing University of Science and Technology for his assistance in FT-IR measurement.

\section{Authors' contributions}

$X C, R Z, Y L$ and $X Y$ performed the experiments, and analyzed the data; Mingjie Jin coordinated and supervised this study; XC, RZ, Z-HL and MJ drafted and revised the manuscript. All authors read and approved the final manuscript.

\section{Funding}

This work was supported by "National Key R\&D Program of China", Grant No. 2016YFE0105400, "Natural Science Foundation of Jiangsu Province", Grant Nos. BK20170037 and BK20170832, "National Natural Science Foundation of China", Grant Nos. 21606132 and 21908111, "The Fundamental Research Funds for the Central Universities", Grant No. 30916011202 and Grant No. 30919011215 , and the Foundation of Jiangsu Specially Appointed Professor.

\section{Availability of data and materials}

All data generated or analyzed during this study are included.

Ethical approval and consent to participate

Not applicable.

\section{Consent for publication}

Not applicable.

\section{Competing interests}

The authors declare that they have no competing interests. 


\section{Author details}

1 School of Environmental and Biological Engineering, Nanjing University of Science and Technology, 200 Xiaolingwei Street, Xuanwu District, Nanjing 210094, China. ${ }^{2}$ Department of Plant Pathology and Microbiology, College of Agriculture and Life Sciences, Texas A\&M University, College Station, TX 77843, USA.

Received: 21 October 2019 Accepted: 22 February 2020 Published online: 11 March 2020

\section{References}

1. Fang X, Shen Y, Zhao J, Bao X, Qu Y. Status and prospect of lignocellulosic bioethanol production in China. Bioresour Technol. 2010;101(13):4814-9.

2. Yang B, Wyman CE. Pretreatment: the key to unlocking low-cost cellulosic ethanol. Biofuel Bioprod Biorefin. 2008;2(1):26-40.

3. Oliva-Taravilla A, Tomas-Pejo E, Demuez M, Gonzalez-Fernandez C, Ballesteros M. Phenols and lignin: key players in reducing enzymatic hydrolysis yields of steam-pretreated biomass in presence of laccase. J Biotechnol. 2016;218:94-101.

4. Adeboye PT, Bettiga M, Olsson L. The chemical nature of phenolic compounds determines their toxicity and induces distinct physiological responses in Saccharomyces cerevisiae in lignocellulose hydrolysates. AMB Express. 2014;4:46.

5. Sun C, Xia A, Liao Q, Guo X, Fu Q, Huang Y, Zhu X, Ding L, Chen C. Inhibitory effects of furfural and vanillin on two-stage gaseous biofuel fermentation. Fuel. 2019;252:350-9.

6. Kumar R, Wyman CE. Effect of enzyme supplementation at moderate cellulase loadings on initial glucose and xylose release from corn stover solids pretreated by leading technologies. Biotechnol Bioeng. 2009;102(2):457-67.

7. Ximenes E, Kim Y, Mosier N, Dien B, Ladisch M. Inhibition of cellulases by phenols. Enzyme Microb Technol. 2010;46(3-4):170-6.

8. Qing Q, Wyman CE. Hydrolysis of different chain length xylooliogmers by cellulase and hemicellulase. Bioresour Technol. 2011;102(2):1359-66.

9. Zhang J, Viikari L. Xylo-oligosaccharides are competitive inhibitors of cellobiohydrolase I from Thermoascus aurantiacus. Bioresour Technol. 2012;117:286-91.

10. Yi X, Gu H, Gao Q, Liu ZL, Bao J. Transcriptome analysis of Zymomonas mobilis ZM4 reveals mechanisms of tolerance and detoxification of phenolic aldehyde inhibitors from lignocellulose pretreatment. Biotechnol Biofuels. 2015:8:153.

11. Sun Q, PuY, Meng X, Wells T, Ragauskas AJ. Structural transformation of isolated poplar and switchgrass lignins during dilute acid treatment. ACS Sustai Chem Eng. 2015;3(9):2203-10.

12. Zhai R, Hu J, Saddler JN. Minimizing cellulase inhibition of whole slurry biomass hydrolysis through the addition of carbocation scavengers during acid-catalyzed pretreatment. Bioresour Technol. 2018;258:12-7.

13. Qin L, Li WC, Liu L, Zhu JQ, Li X, Li BZ, Yuan YJ. Inhibition of lignin-derived phenolic compounds to cellulase. Biotechnol Biofuels. 2016;9:70.

14. Ezeji T, Qureshi N, Blaschek HP. Butanol production from agricultural residues: impact of degradation products on Clostridium beijerinckii growth and butanol fermentation. Biotechnol Bioeng. 2007;97(6):1460-9.

15. Adeboye PT, Bettiga M, Aldaeus F, Larsson PT, Olsson L. Catabolism of coniferylaldehyde, ferulic acid and $p$-coumaric acid by Saccharomyces cerevisiae yields less toxic products. Microb Cell Fact. 2015;14:149.

16. Fitzgerald DJ, Stratford M, Gasson MJ, Ueckert J, Bos A, Narbad A. Mode of antimicrobial action of vanillin against Escherichia coli, Lactobacillus plantarum and Listeria innocua. J Appl Microbiol. 2004;97(1):104-13.

17. Wu L, Arakane M, Ike M, et al. Low temperature alkali pretreatment for improving enzymatic digestibility of sweet sorghum bagasse for ethanol production. Bioresour Technol. 2011;102(7):4793-9.

18. Humpula JF, Uppugundla N, Vismeh R, Sousa L, Chundawat SP, Jones AD, Balan V, Dale BE, Cheh AM. Probing the nature of AFEX-pretreated corn stover derived decomposition products that inhibit cellulase activity. Bioresour Technol. 2014;152:38-45.

19. Ko JK, Kim Y, Ximenes E, et al. Effect of liquid hot water pretreatment severity on properties of hardwood lignin and enzymatic hydrolysis of cellulose. Biotechnol Bioeng. 2015;112(2):252-62.
20. Kim S, Kim T, Oh K. Deacetylation followed by fractionation of yellow poplar sawdust for the production of toxicity-reduced hemicellulosic sugar for ethanol fermentation. Energies. 2018;11(2):404.

21. Klinke HB, Thomsen AB, Ahring BK. Inhibition of ethanol-producing yeast and bacteria by degradation products produced during pre-treatment of biomass. Appl Microbiol Biotechnol. 2004;66(1):10-26.

22. Zhai R, Hu J, Saddler JN. Extent of enzyme inhibition by phenolics derived from pretreated biomass is significantly influenced by the size and carbonyl group content of the phenolics. ACS Sustain Chem Eng. 2018;6(3):3823-9.

23. Huang C, Wang X, Liang C, Jiang X, Yang G, Xu J, Yong Q. A sustainable process for procuring biologically active fractions of high-purity xylooligosaccharides and water-soluble lignin from Moso bamboo prehydrolyzate. Biotechnol Biofuels. 2019;12(1):189.

24. Rasmussen H, Tanner D, Sørensen HR, Meyer AS. New degradation compounds from lignocellulosic biomass pretreatment: routes for formation of potent oligophenolic enzyme inhibitors. Green Chem. 2017;19(2):464-73.

25. Hsieh CWC, David C, Henning JR, Claus F, Thygesen LG. Cellulase inhibition by high concentrations of monosaccharides. J Agric Food Chem. 2014;62(17):3800.

26. Franden MA, Pienkos PT, Zhang M. Development of a high-throughput method to evaluate the impact of inhibitory compounds from lignocelIulosic hydrolysates on the growth of Zymomonas mobilis. J Biotechnol. 2009;144(4):259-67.

27. Sarks C, Bals BD, Wynn J, Teymouri F, Schwegmann S, Sanders K, Jin M, Balan $V$, Dale BE. Scaling up and benchmarking of ethanol production from pelletized pilot scale AFEX treated corn stover using Zymomonas mobilis 8b. Biofuels. 2016;7(3):253-62.

28. Tana T, Zhang Z, Moghaddam L, Rackemann DW, Rencoret J, Gutiérrez A, del Río JC, Doherty WOS. Structural changes of sugar cane bagasse lignin during cellulosic ethanol production process. ACS Sustain Chem Eng. 2016:4(10):5483-94.

29. Lui MY, Chan B, Yuen AKL, Masters AF, Montoya A, Maschmeyer T. Unravelling some of the key transformations in the hydrothermal liquefaction of lignin. Chemsuschem. 2017;10(10):2140-4.

30. Feng N, Ren L, Wu H, Wu Q, Xie Y. New insights on structure of lignincarbohydrate complex from hot water pretreatment liquor. Carbohydr Polym. 2019;224:115130.

31. Xue S, Jones AD, Sousa L, Piotrowski J, Jin M, Sarks C, Dale BE, Balan V. Water-soluble phenolic compounds produced from extractive ammonia pretreatment exerted binary inhibitory effects on yeast fermentation using synthetic hydrolysate. PLOS ONE. 2018;13(3):e0194012.

32. Wu J, Collins SRA, Elliston A, Wellner N, Dicks J, Roberts IN, Waldron KW. Release of cell wall phenolic esters during hydrothermal pretreatment of rice husk and rice straw. Biotechnol Biofuels. 2018;11:162.

33. Shen X-J, Wang B, Pan-li H, Wen J-L, Sun R-C. Understanding the structural changes and depolymerization of Eucalyptus lignin under mild conditions in aqueous AICI3. RSC Adv. 2016;6(51):45315-25.

34. Liu C, Hu J, Zhang H, Xiao R. Thermal conversion of lignin to phenols: relevance between chemical structure and pyrolysis behaviors. Fuel. 2016;182:864-70.

35. Yang X, Ma F, Zeng Y, Yu H, Xu C, Zhang X. Structure alteration of lignin in corn stover degraded by white-rot fungus Irpex lacteus CD2. Int Biodeterior Biodegradation. 2010;64(2):119-23.

36. Lee JM, Jameel $H$, Venditti RA. A comparison of the autohydrolysis and ammonia fiber explosion (AFEX) pretreatments on the subsequent enzymatic hydrolysis of coastal Bermuda grass. Bioresour Technol. 2010;101(14):5449-58.

37. Chundawat SP, Donohoe BS, da Costa Sousa L, Elder T, Agarwal UP, Lu F, Ralph J, Himmel ME, Balan V, Dale BE. Multi-scale visualization and characterization of lignocellulosic plant cell wall deconstruction during thermochemical pretreatment. Energy Environ Sci. 2011;4(3):973.

38. Franden MA, Pilath HM, Mohagheghi A, Pienkos PT, Zhang M. Inhibition of growth of Zymomonas mobilis by model compounds found in lignocellulosic hydrolysates. Biotechnol Biofuels. 2013;6(1):99.

39. Tang X, da Sousa L, Jin M, Chundawat SPS, Chambliss CK, Lau MW, Xiao Z, Dale BE, Balan V. Designer synthetic media for studying microbialcatalyzed biofuel production. Biotechnol Biofuels. 2015;8(1):1. 
40. Chen X, Zhai R, Shi K, Yuan Y, Dale BE, Gao Z, Jin M. Mixing alkali pretreated and acid pretreated biomass for cellulosic ethanol production featuring reduced chemical use and decreased inhibitory effect. Ind Crops Prod. 2018;124:719-25.

41. Rover MR, Brown RC. Quantification of total phenols in bio-oil using the Folin-Ciocalteu method. J Analy Appl Pyrolys. 2013;104:366-71.

42. Keating DH, Zhang Y, Ong IM, Mcllwain S, Morales EH, Grass JA, Tremaine M, Bothfeld W, Higbee A, Ulbrich A, Balloon AJ, Westphall MS, Aldrich J, Lipton MS, Kim J, Moskvin OV, Bukhman YV, Coon JJ, Kiley PJ, Bates DM, Landick R. Aromatic inhibitors derived from ammonia-pretreated lignocellulose hinder bacterial ethanologenesis by activating regulatory circuits controlling inhibitor efflux and detoxification. Front Microbiol. 2014;5:402.

43. Uppugundla N, Leonardo DCS, Chundawat SP, et al. A comparative study of ethanol production using dilute acid, ionic liquid and AFEX ${ }^{\mathrm{TM}}$ pretreated corn stover. Biotechnol Biofuels. 2014;7(1):72.
44. B. Hames, R.R., C. Scarlata, A. Sluiter, J. Sluiter, and D. Templeton. Preparation of Samples for Compositional Analysis Laboratory Analytical Procedure (LAP). Natl Renew Energy Lab. 2008; 1-9.

45. Zeng M, Mosier NS, Huang CP, Sherman DM, Ladisch MR. Microscopic examination of changes of plant cell structure in corn stover due to hot water pretreatment and enzymatic hydrolysis. Biotechnol Bioeng. 2007;97(2):265-78.

46. Chen LY, Cheng CW, Liang JY. Effect of esterification condensation on the Folin-Ciocalteu method for the quantitative measurement of total phenols. Food Chem. 2015;170:10-5.

\section{Publisher's Note}

Springer Nature remains neutral with regard to jurisdictional claims in published maps and institutional affiliations.
Ready to submit your research? Choose BMC and benefit from:

- fast, convenient online submission

- thorough peer review by experienced researchers in your field

- rapid publication on acceptance

- support for research data, including large and complex data types

- gold Open Access which fosters wider collaboration and increased citations

- maximum visibility for your research: over $100 \mathrm{M}$ website views per year

At BMC, research is always in progress.

Learn more biomedcentral.com/submissions 